\title{
ANALYSIS OF OPTICAL PROPERTIES OF LABORATORY PAPERS MADE FROM STRAW PULP AND COATED WITH TITANIUM DIOXIDE WHITE INK
}

\author{
VALENTINA RADIĆ SELEŠ, IRENA BATES, IVANA PLAZONIĆ and \\ IGOR MAJNARIĆ \\ University of Zagreb, Faculty of Graphic Arts, 10000, Zagreb, Croatia \\ $\bowtie$ Corresponding author: I. Bates, irena.bates@grf.hr
}

Received December 12, 2019

Considering that optical properties play a very important role in the printing industry, this research focused on analysing the optical properties (opacity, whiteness, brightness and yellowness) of laboratory made papers from recycled wood pulp, with the addition of different straw contents, coated with titanium dioxide white ink. Titanium dioxide white ink was applied on laboratory papers to achieve optical characteristics as those of commercial papers recommended by ISO 12647. All the coated laboratory papers presented whiteness within the recommendations of the standard. Almost all the coated papers made with the addition of straw pulp achieved satisfactory optical properties, especially those containing $10 \%$ and $20 \%$ straw pulp. Coated laboratory papers containing $10 \%$ and $20 \%$ wheat pulp were comparable to commercial paper and reached a similar value of brightness, while their opacity and yellowness values were even better than those of commercial paper. In order to preserve the natural appearance of papers made with the addition of straw pulp, it is possible to conduct selective white printing as background for high-quality printing.

Keywords: opacity, whiteness, brightness, yellowness, titanium dioxide, straw pulp

\section{INTRODUCTION}

In accordance with the EU's environmental directives, the production of paper and board is increasingly focused on alternative non-wood materials. Given that the paper industry is still using wood as a major source of fibre supply, it is wise to replace it as much as possible with other plant biomasses by utilizing non-wood fibre materials to produce cellulose pulps. ${ }^{1}$ Straw as a by-product of crop farming could be used as an environmentally friendly and economical supplement to wood in terms of fibre supply, as it has numerous advantages, namely its abundance and renewability. Wheat, barley and triticale straws are a good fibre material, produced annually in huge quantities worldwide in a much shorter growing cycle than wood. After proper pulping and cleaning, the pulps from these straws can be used for manufacturing various paper products. ${ }^{1}$

Naturally, any paper used for printing must have good optical properties, such as opacity, whiteness, brightness and yellowness. Opacity (the degree of non-transparency) is a fundamental property of paper as a whole, yet the measurement of opacity is determined by the ratio of reflectance. The opacity of a sheet is influenced by its thickness, the amount and kind of filler, degree of fibre bleaching, coating etc. ${ }^{3}$ For a quality print, it is necessary that the opacity exceeds $80 \%$. The highest print quality is determined by high whiteness values, specifically, ISO whiteness values from 140 to 175 , and it is also important to understand that opacity is related to other optical properties, such as brightness and Y-value. $^{4}$ Brightness is the numerical value of the reflectance factor of a sample with respect to blue light of specific spectral and geometric characteristics. This method is used for the determination of the brightness of white, near white and naturally coloured pulp, paper and paperboard. Whiteness is a subjectively perceived property and most people consider that it increases when the material has a slightly blue tone. It is thus clear that the 


\section{VALENTINA RADIĆ SELEŠ et al.}

whiteness is in some way an aspect of colour perception, and that any measurement of whiteness must be based on colour measurement. Whiteness is based on the reflectance data obtained over the full visible spectral range, in contrast to brightness measurement, which is limited to the nominal wavelength of $457 \mathrm{~nm}$ reflected from the measured surface, therefore whiteness could provide more reliable information on the observed whiteness of the paper. ${ }^{5}$ Yellowness is defined as a measure of the degree to which the colour of a surface is shifted from preferred white (or colourless) towards yellow. Yellowness was developed specifically for determining the yellowness of homogeneous, non-fluorescent, nearly colourless, transparent, nearly white translucent, or opaque plastics (as viewed under daylight lightning conditions), but can also be applied to materials other than plastic fitting this description. ${ }^{6}$

In general, printing paper goes through a bleaching process during production. However, if viewed from another perspective, especially for smaller production, the paper whitening process could be done differently, in terms of paper coating with white pigments. Pigments, together with dyestuffs, are probably the most important items in printing ink and each pigment is identified by names in common use, followed by the first colour index number. White pigments and extenders have been described separately from other pigments, as a special description of types and other properties is essential. Titanium dioxide $\left(\mathrm{TiO}_{2}\right)$ is the most important white pigment currently in use. It has replaced nearly all other whites, as it has exceptional resistance qualities, being a very lightfast and heat resistant inert material. ${ }^{7}$ Titanium dioxide as a white powder pigment is mainly used in products, such as paints, coatings, plastics, paper, inks, fibres, food and cosmetics, due to its brightness and high refractive index $(>2.4)$. It occurs as an odourless, colourless to white crystalline powder in two forms: anatase and rutile. Anatase pigments are used more in liquid printing inks due to their softer structure. Rutile pigments have a higher refractive index, higher opacity and a somewhat rougher structure. ${ }^{8}$ Commercial titanium dioxide pigment is produced either by the sulphate process or by the chloride process. ${ }^{9}$

\section{EXPERIMENTAL \\ Materials}

Laboratory papers were formed from recycled wood pulp with the addition of different contents of straw pulp obtained from agricultural residues of three different annual crops: wheat, barley and triticale. According to the soda method, the straw cut to $1-3 \mathrm{~cm}$ length was converted into semi-chemical pulp. ${ }^{10}$ The conditions for the soda method are presented in Table 1.

The obtained unbleached straw pulp was mixed with recycled wood pulp in different weight ratios $(10 \%, 20 \%$ and $30 \%$ for each straw). In this research, commercial paper for newsprint was used as the basic component, respectively as recycled wood pulp. Newsprint paper characteristics are listed in Table $2 .^{10}$ Laboratory papers were formed on a Rapid Köthen sheet former (FRANK-PTI GmbH, Birkenau, Germany) according to EN ISO 526 9-2:2001 standard and weighed approximately $42.5 \mathrm{~g}^{-2}$. In total, 10 types of laboratory papers were formed. Paper PS7 as per ISO 12647-2 standard $^{11}$ was used as reference paper for comparing the optical properties of papers containing straw pulp, such as whiteness and colorimetric difference values; and commercial paper cPS7 was used as reference paper for determining opacity, brightness and yellowness values. Abbreviations used in marking all samples are listed in Table 3.

\section{Methods \\ Weight determination}

All the samples were weighed before and after coating, to determine the amount of $\mathrm{TiO}_{2}$ white ink on each paper in grams. Measurement was carried out with a Mettler Toledo KS205DU Dual Range Analytic Scale, which allows measurement in the range of 0-220 $\mathrm{g}$, with a precision of $0.01 \mathrm{mg}$.

Table 1

Operating conditions of straw pulping

\begin{tabular}{lccc}
\hline Agricultural residues & Pulping method & \multicolumn{2}{c}{ Extraction conditions } \\
\hline Wheat straw & Temperature & $120^{\circ} \mathrm{C}$ \\
Barley straw & Soda pulping & Alkali level of $16 \%$ & $60 \mathrm{~min}$ \\
Triticale straw & & Biomass ratio & $10: 1$ \\
\hline
\end{tabular}


Table 2

Properties of commercial UPM News C paper

\begin{tabular}{|c|c|c|}
\hline \multicolumn{2}{|c|}{ Basis weight (ISO 536), $\mathrm{g}^{-2}$} & 42.5 \\
\hline \multicolumn{2}{|c|}{ Brightness D65 (ISO 2470-2), \% } & 58.0 \\
\hline \multicolumn{2}{|c|}{ Roughness Bendtsen (ISO 8791-2), $\mathrm{mL} \mathrm{min}^{-1}$} & $100.0-160.0$ \\
\hline \multirow{2}{*}{$\mathrm{R}_{\mathrm{a}}(\mathrm{ISO} 4287-1), \%$} & Machine direction (MD) & $2.576 \pm 0.319$ \\
\hline & Cross machine direction (CD) & $3.166 \pm 0.254$ \\
\hline Ash (ISO 2144), \% & & $10.00 \pm 0.04$ \\
\hline CWSN & & $9 \mathrm{~A}$ \\
\hline
\end{tabular}

Table 3

Abbreviations used in marking samples

\begin{tabular}{ll}
\hline PS7 & Commercial paper (reference) as per standard ISO 12647-2 \\
cPS7 & Commercial paper (reference) \\
100N & Laboratory paper with 100\% recycled wood pulp \\
90N10W & Laboratory paper with 10\% wheat pulp \\
80N20W & Laboratory paper with 20\% wheat pulp \\
70N30W & Laboratory paper with 30\% wheat pulp \\
90N10B & Laboratory paper with 10\% barley pulp \\
80N20B & Laboratory paper with 20\% barley pulp \\
70N30B & Laboratory paper with 30\% barley pulp \\
90N10T & Laboratory paper with 10\% triticale pulp \\
80N20T & Laboratory paper with 20\% triticale pulp \\
70N30T & Laboratory paper with 30\% triticale pulp \\
\hline
\end{tabular}

Table 4

Components of used Ink jet ink

\begin{tabular}{lc}
\hline Components & Weight (\%) \\
\hline Acrylic esters & $30-40$ \\
Titanium dioxide & $10-20$ \\
Hexamethylene diacrylate & $10-20$ \\
Tri (propylene glycol) diacrylate & $10-20$ \\
Phosphine oxide derivative & $5-15$ \\
Other photo-sensitive monomers & $0-5$ \\
Synthetic resins & $0.5-5$ \\
\hline
\end{tabular}

Table 5

Presentation of particle size, particle shape, refractive index and ISO-brightness for titanium dioxide pigments

\begin{tabular}{|c|c|c|c|c|c|}
\hline Coating pigment & $\begin{array}{l}\text { Particle size } \\
(\mu \mathrm{m})\end{array}$ & Shape & $\begin{array}{c}\text { Crystal } \\
\text { structure }\end{array}$ & $\begin{array}{c}\text { Refractive } \\
\text { index }\end{array}$ & $\begin{array}{c}\text { ISO Brightness } \\
(\%)\end{array}$ \\
\hline $\begin{array}{l}\text { Titanium dioxide } \\
\text { (Anatase) }\end{array}$ & $0.2-0.5$ & Rod-like & & 2.55 & $98-99$ \\
\hline $\begin{array}{l}\text { Titanium dioxide } \\
\text { (Rutile) }\end{array}$ & $0.2-0.5$ & Roundish & $y^{2}$ & 2.7 & $97-99$ \\
\hline
\end{tabular}

\section{Coating laboratory papers with titanium dioxide white ink}

Laboratory papers were coated in one and two layers with titanium dioxide white ink to achieve the same or even better optical characteristics than those of commercial papers (PS7and c PS7). Layers of white ink in full tone were applied to all laboratory papers by a digital Roland Versa UV-LEC 300 Inkjet printing machine, which works on the piezo inkjet principle. 
The ink was a white liquid (producer Roland DG Corporation), with a viscosity of $6-8 \mathrm{mPa} \mathrm{s}$, a characteristic odour and flash point of $66{ }^{\circ} \mathrm{C}$. The components of the used inks, expressed in weight percentages, are presented in Table $4 .^{12}$ Table 5 shows some characteristics of two forms of titanium dioxide. ${ }^{6}$

\section{Optical properties}

To determine the optical properties of the laboratory papers containing straw pulp after coating with titanium dioxide white ink, in comparison with those of commercial papers cPS7 and PS7, several major optical characteristics were analysed. Opacity (TAPPI 425 om-06), ${ }^{3}$ whiteness (ASTM 313), ${ }^{13}$ brightness (TAPPI 452 om-08) (14 $^{14}$ and yellowness (ASTM 313) ${ }^{13}$ were measured with an X-Rite eXact spectrophotometer, with standard illuminate D65, $10^{\circ}$ observer without polarization filter and $\mathrm{M}_{0}\left(\mathrm{~N}_{0}\right)$ filter. Optical measurements were repeated 45 times on each sample.

\section{Colour differences or Euclidean difference $\left(\Delta E_{00} *\right)$}

The Euclidean difference $\left(\Delta \mathrm{E}_{00} *\right)$ of all the analysed laboratory papers, uncoated and coated with one or two layers of titanium dioxide white ink, was calculated based on measured colorimetric CIE $\mathrm{L}^{*} \mathrm{a} \mathrm{b}^{*}$ values, which were determined by the X-Rite eXact spectrophotometer. In the CIE L*a*b* colour space, the value $\mathrm{L}^{*}$ represents the lightness of the colour, value $+\mathrm{a}^{*}$ represents redness, value $-\mathrm{a}^{*}$ represents greenness, value $+b^{*}$ represents yellowness and value $-b^{*}$ represents blueness. ${ }^{15}$ The colour differences of all the examined laboratory papers were calculated by the following equation using the characteristics of commercial paper PS7 as per ISO 12647-2 standard as reference:

$\Delta E_{00}^{*}=\left(\frac{\Delta L^{\prime}}{k_{L} S_{L}}\right)^{2}+\left(\frac{\Delta C^{f}}{k_{e} S_{e}}\right)^{2}+\left(\frac{\Delta H^{B}}{k_{H} S_{H}}\right)^{2}+R_{T} \frac{\Delta C^{\prime}}{k_{C} S_{C}} \frac{\Delta H^{\prime}}{k_{C} S_{H}}$

where $\Delta L^{\prime}$ is the transformed lightness difference between the laboratory paper and commercial paper PS7, $\Delta C^{\prime}$ is the transformed Chroma difference between the laboratory paper and commercial paper PS7, $\Delta H^{\prime}$ is the transformed hue difference between the laboratory paper and commercial paper PS7, $R_{T}$ is the rotation function, $k_{L}, k_{C}$ and $k_{H}$ are the parametric factors for variation in the experimental conditions and $S_{L}, S_{C}, S_{H}$ are the weighting functions. ${ }^{16}$ Tolerances of the colorimetric differences $\left(\Delta \mathrm{E}^{*}{ }_{00}\right)$ are presented in Table $6 .{ }^{17}$

The entire workflow in this research, from papermaking to final analysis is presented in Figure 1.

\section{RESULTS AND DISCUSSION Weight determination}

For defining the weight of white ink coating, the Inkjet nozzle distributed $2 \mathrm{pl}$ of white ink on paper substrates, which were then dried by LED UV technology.
Weight determination of the titanium dioxide white ink coating was conducted on all the analysed laboratory papers, one layer $\Delta \mathrm{w}_{1}=\mathrm{w}_{\text {llayer }}$ coated $-\mathrm{W}_{\text {uncoated(a) }}$ and two layers $\Delta \mathrm{w}_{2}=\mathrm{w}_{2 \text { layer coated }}$ - $\mathrm{w}_{\text {uncoated(b). The initial paper sample before }}$ coating with one layer of $\mathrm{TiO}_{2}$ ink is marked as "a" and the paper sample before coating with two ink layers is marked as "b" in Table 7.

\section{Opacity}

Figures 2-4 present the opacity values of all the analysed papers, before and after coating with one or two layers of titanium dioxide white ink. The opacity values of the laboratory papers were compared to those of commercial paper cPS7. From the opacity values obtained for all the laboratory papers containing wheat pulp (Fig. 2), it is evident that the laboratory paper containing $10 \%$ wheat pulp $(90 \mathrm{~N} 10 \mathrm{~W})$ has the highest opacity after coating with one and two layers of titanium dioxide white ink. The laboratory papers made from $100 \%$ recycled wood pulp $(100 \mathrm{~N})$ have the lowest opacity of all, while the uncoated laboratory paper with $20 \%$ wheat pulp ( $80 \mathrm{~N} 20 \mathrm{~W})$ has the highest opacity value.

With reference to laboratory papers with barley pulp, Figure 3 shows that the highest opacity value is achieved on the laboratory paper with $10 \%$ barley pulp (90N10B) coated with two layers of titanium dioxide white ink and the laboratory paper containing $20 \%$ barley pulp $(80 \mathrm{~N} 20 \mathrm{~B})$ coated with one layer of titanium dioxide white ink. Among uncoated papers, 80 N20B has the highest opacity value. In Figure 4 , it is visible that the laboratory paper made from $100 \%$ wood pulp and the laboratory paper containing $20 \%$ triticale pulp $(80 \mathrm{~N} 20 \mathrm{~T})$ coated with two layers of titanium dioxide white ink have the highest opacity values. The papers with the highest opacity values after applying one layer of titanium dioxide white ink are laboratory papers $100 \mathrm{~N}, 90 \mathrm{~N} 10 \mathrm{~T}$ and $80 \mathrm{~N} 20 \mathrm{~T}$. For uncoated papers, the highest opacity value is noticeable on the laboratory paper containing $20 \%$ triticale pulp.

\section{Whiteness}

Figures 5-7 present the whiteness values of all the analysed papers, before and after coating with one or two layers of titanium dioxide white ink. The grey area - whiteness from 40 to 80 represents the range of values within the ISO 12647-2 standard for whiteness of commercial paper PS7. The measured whiteness value of commercial paper cPS7 is at the upper limit of the 
values recommended by ISO 12647-2 standard. The whiteness values of all the laboratory papers containing wheat pulp presented in Figure 5 indicate that the laboratory papers containing $10 \%$ wheat pulp achieve the highest whiteness value after coating with one and two layers of titanium dioxide white ink.

Table 6

Tolerances of Euclidean differences

\begin{tabular}{cc}
\hline Euclidean difference value & Euclidean difference tolerance \\
\hline$<1$ & Average human eye does not see the difference \\
$1-2$ & Very small difference - optimal $\Delta \mathrm{E}_{00}^{*}=2$ \\
$2-3$ & Moderate difference \\
$3.5-5$ & Difference \\
$>5$ & Great difference \\
\hline
\end{tabular}

\begin{tabular}{|c|c|}
\hline $\begin{array}{c}\text { Recycled } \\
\text { wood }\end{array}$ & $\begin{array}{c}W_{\text {pulp }}, \% \\
\text { Straw } \\
\text { (wheat, barley or } \\
\text { triticale) }\end{array}$ \\
\hline 100 & 0 \\
\hline 90 & 10 \\
\hline 80 & 20 \\
\hline 70 & 30 \\
\hline
\end{tabular}
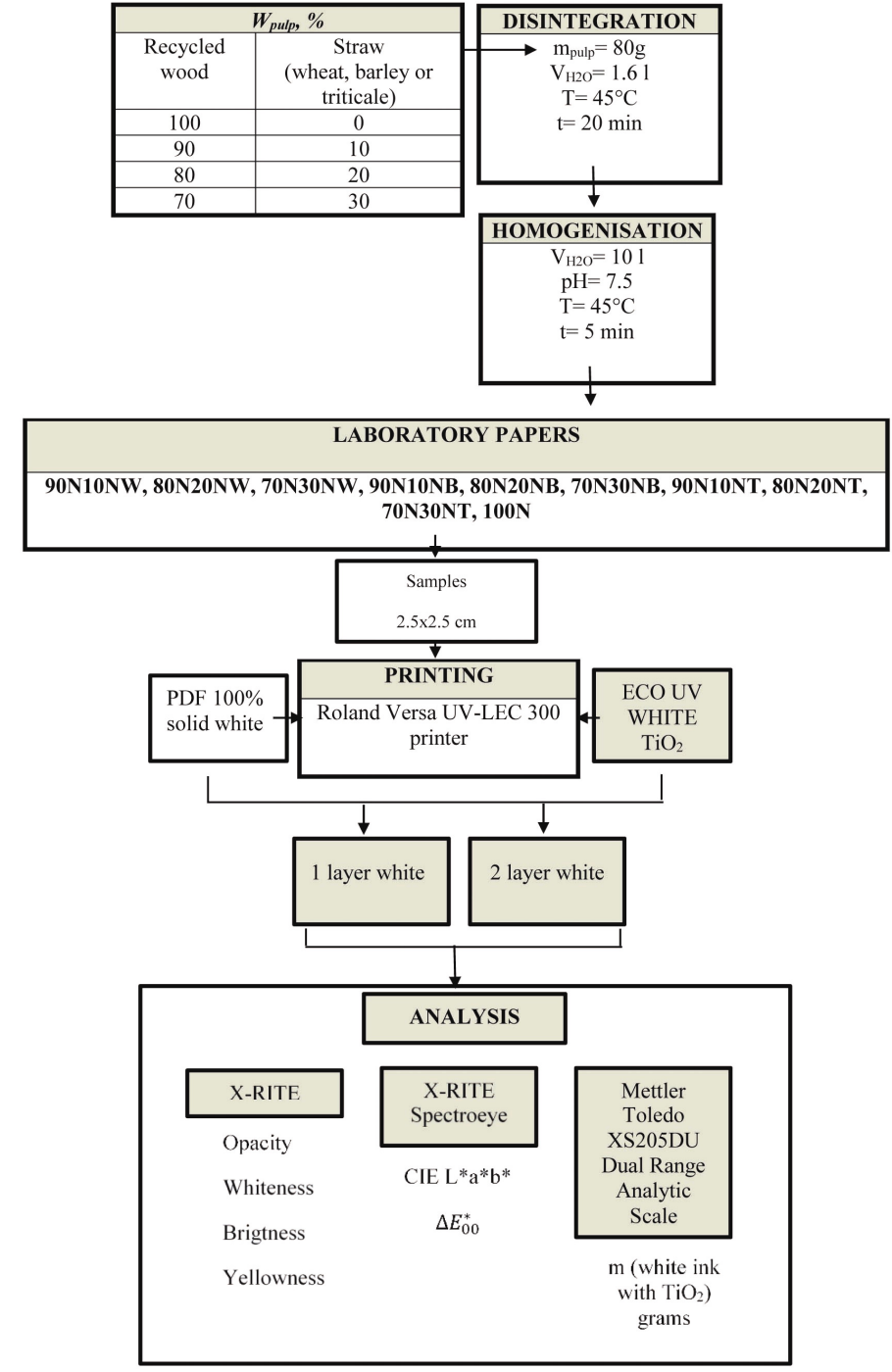

Figure 1: Workflow 


\section{VALENTINA RADIĆ SELEŠ et al.}

Table 7

Titanium dioxide weight in grams on all laboratory papers

\begin{tabular}{lccccc}
\hline \multirow{2}{*}{$\begin{array}{l}\text { Laboratory } \\
\text { papers }\end{array}$} & \multicolumn{2}{c}{$\begin{array}{c}\text { Mass }(\mathrm{m}) \text { of uncoated papers } \\
(\mathrm{g})\end{array}$} & \multicolumn{3}{c}{$\begin{array}{c}\text { Mass }(\mathrm{m}) \text { of white ink based on titanium } \\
\text { dioxide }(\mathrm{g})\end{array}$} \\
\cline { 2 - 6 } & $\mathrm{a}$ & $\mathrm{b}$ & $\Delta \mathrm{w}_{1}$ & $\Delta \mathrm{w}_{2}$ & $\Delta \mathrm{w}_{2}-\Delta \mathrm{w}_{1}$ \\
\hline 100N & 0.028 & 0.028 & 0.007 & 0.014 & 0.007 \\
90N10W & 0.029 & 0.030 & 0.007 & 0.014 & 0.007 \\
80N20W & 0.030 & 0.030 & 0.007 & 0.014 & 0.007 \\
70N30W & 0.030 & 0.031 & 0.007 & 0.013 & 0.006 \\
90N10B & 0.032 & 0.031 & 0.007 & 0.013 & 0.006 \\
80N20B & 0.032 & 0.026 & 0.007 & 0.018 & 0.011 \\
70N30B & 0.029 & 0.029 & 0.006 & 0.013 & 0.007 \\
90N10T & 0.028 & 0.028 & 0.007 & 0.013 & 0.006 \\
80N20T & 0.029 & 0.030 & 0.006 & 0.013 & 0.007 \\
70N30T & 0.027 & 0.027 & 0.006 & 0.013 & 0.007 \\
\hline
\end{tabular}

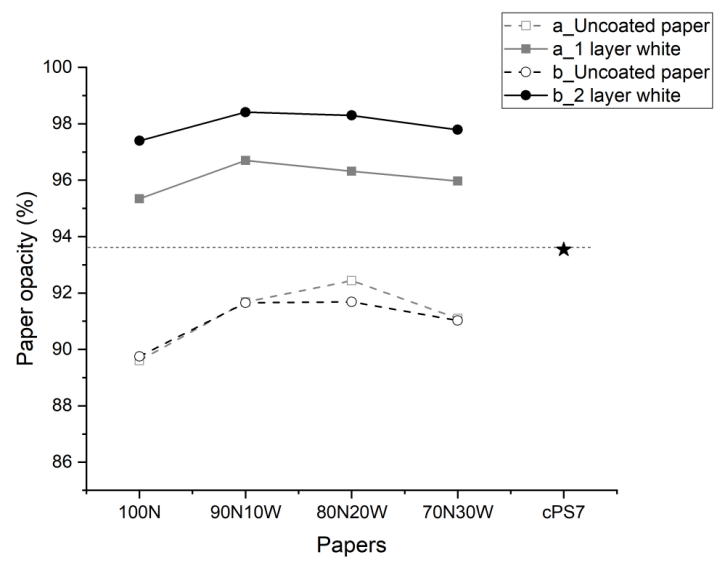

Figure 2: Influence of coating with titanium dioxide white ink on opacity of laboratory papers with wheat pulp compared to commercial paper cPS7

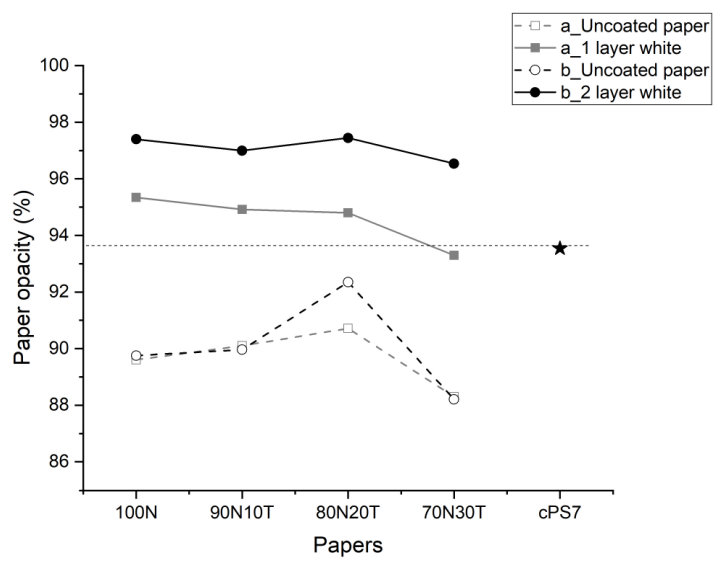

Figure 4: Influence of coating with titanium dioxide white ink on opacity of laboratory papers with triticale pulp compared to commercial paper cPS7

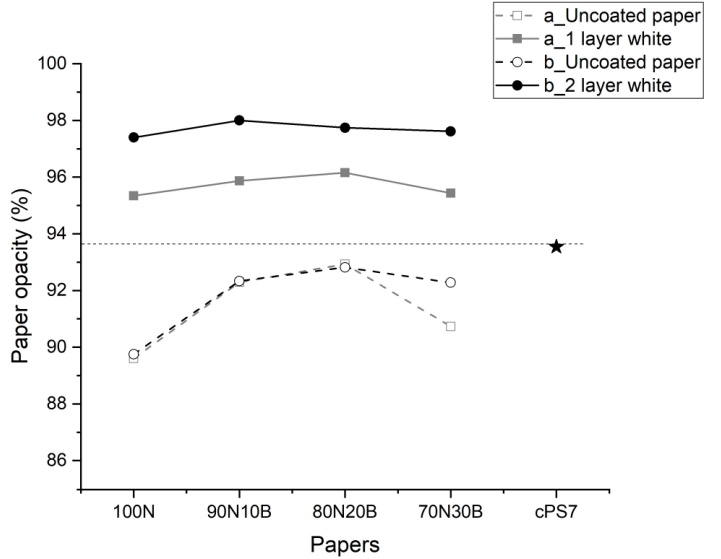

Figure 3: Influence of coating with titanium dioxide white ink on opacity of laboratory papers with barley pulp compared to commercial paper cPS7

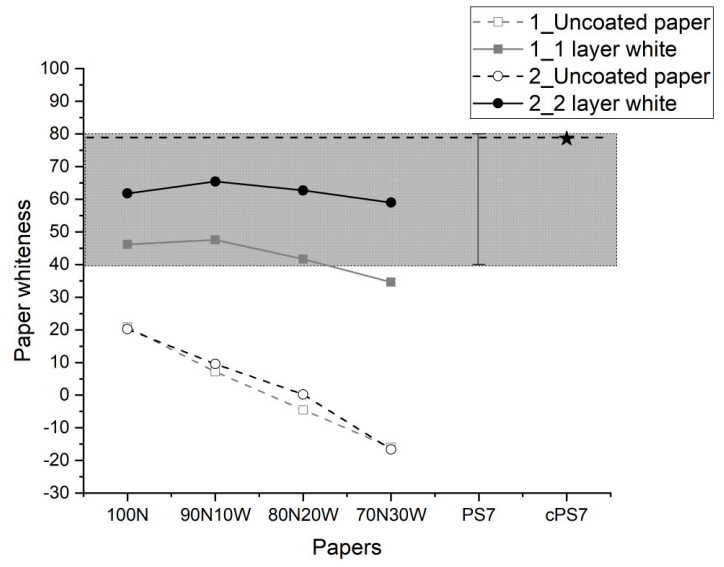

Figure 5: Influence of coating with titanium dioxide white ink on whiteness of laboratory papers with wheat pulp compared to commercial papers PS $7^{11}$ and cPS7 


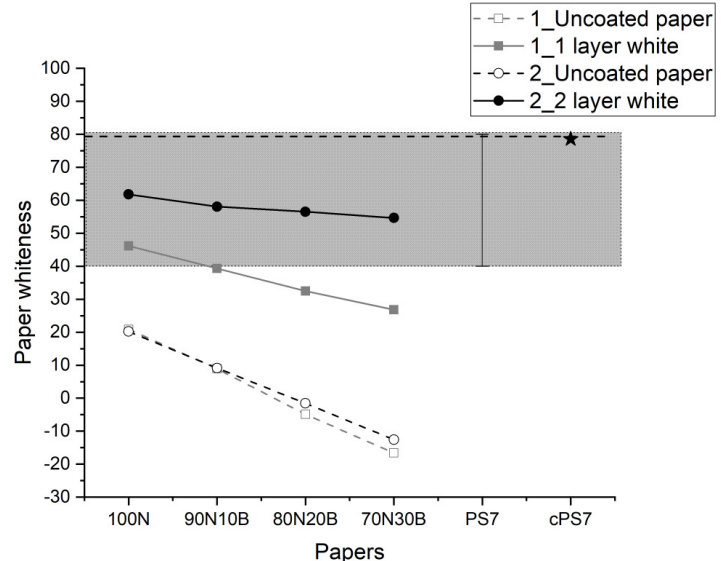

Figure 6: Influence of coating with titanium dioxide white ink on whiteness of laboratory papers with barley pulp compared to commercial papers PS $7^{11}$ and cPS7

Coated laboratory papers with $30 \%$ wheat pulp have the lowest whiteness values of all. Of all uncoated laboratory papers, the one made from $100 \%$ recycled wood pulp $(100 \mathrm{~N})$ has the highest whiteness value, which was expected, as the added straw pulp was not subjected to the bleaching process. Figure 6 shows that the highest whiteness values are recorded for laboratory paper $100 \mathrm{~N}$ coated with one and two layers of titanium dioxide white ink. Among uncoated papers, again laboratory paper $100 \mathrm{~N}$ has the highest whiteness value. Of all papers containing barley pulp, coated and uncoated, the highest whiteness values are observed for the laboratory papers with $10 \%$ barley pulp. In Figure 7, a similar pattern is visible as in Figure 6, where laboratory papers made from $100 \%$ recycled wood pulp (coated and uncoated) have the highest whiteness values. Among the papers containing triticale pulp, coated and uncoated, the highest whiteness values are noted for the laboratory papers with $10 \%$ triticale pulp.

\section{Brightness}

Figures 8-10 present the brightness values of all the analysed papers, before and after coating with one or two layers of titanium dioxide white ink. The brightness values of the laboratory papers were compared to those of commercial paper cPS7, whose measured brightness was 75.5. From the brightness values of all the laboratory papers containing wheat pulp (Fig. 8), it may be

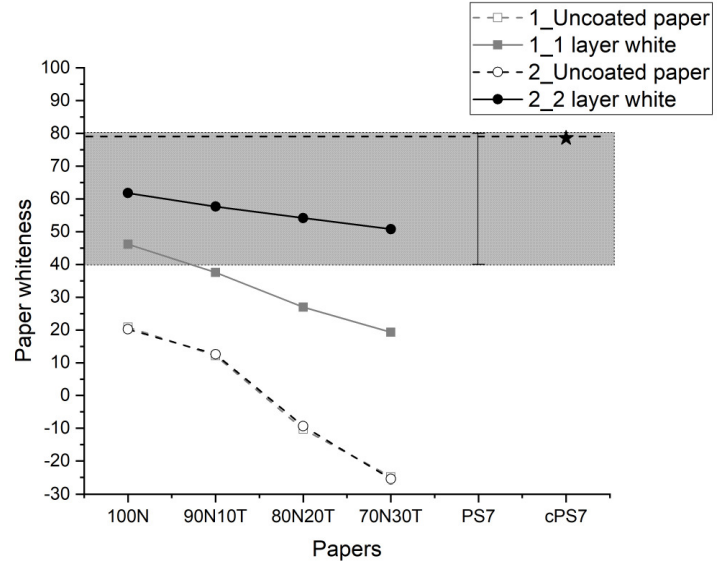

Figure 7: Influence of coating with titanium dioxide white ink on whiteness of laboratory papers with triticale pulp compared to commercial papers $\mathrm{PS} 7^{11}$ and cPS7

noted that the laboratory paper containing $10 \%$ wheat pulp reaches the highest brightness value after coating with two layers of titanium dioxide white ink. Laboratory papers $100 \mathrm{~N}$ and $90 \mathrm{~N} 10 \mathrm{~W}$ coated with one layer of titanium dioxide achieve approximately the same value of brightness, which is the highest measured value on all the papers coated with one layer. Coated and uncoated laboratory papers with $30 \%$ wheat pulp have the lowest brightness values of all. Of all uncoated laboratory papers, the one made from $100 \%$ recycled wood pulp has the highest brightness value. Figure 9 shows that the highest brightness values were measured on laboratory paper $100 \mathrm{~N}$ coated with one or two layers of titanium dioxide white ink. Among uncoated papers, again laboratory paper $100 \mathrm{~N}$ has the highest brightness value. Of all the papers containing barley pulp, coated and uncoated, the highest brightness values were noted for the laboratory papers with $10 \%$ barley pulp. Figure 10 shows that the laboratory papers made from $100 \%$ wood pulp (coated and uncoated) also have the highest brightness values. Among papers containing triticale pulp, coated and uncoated, the highest whiteness values were recorded for the laboratory papers with $10 \%$ triticale pulp. These brightness results obtained for uncoated papers were expected since unbleached straw pulp (wheat, barley and triticale) was used to form laboratory papers. 


\section{VALENTINA RADIĆ SELEŠ et al.}

\section{Yellowness}

Figures 11-13 present the yellowness values of all the analysed papers, before and after coating with one or two layers of titanium dioxide white ink. The yellowness values of all the laboratory papers were compared to those of commercial paper cPS7. Namely, the yellowness of cPS7 paper was by far the highest from all the analysed laboratory papers (uncoated and coated ones, regardless of their composition).

From Figure 11, it is clearly visible that the laboratory papers containing $10 \%$ wheat pulp have the lowest yellowness values after coating with one and two layers of titanium dioxide white ink. Among uncoated papers, laboratory paper $100 \mathrm{~N}$ has the lowest measured yellowness value.

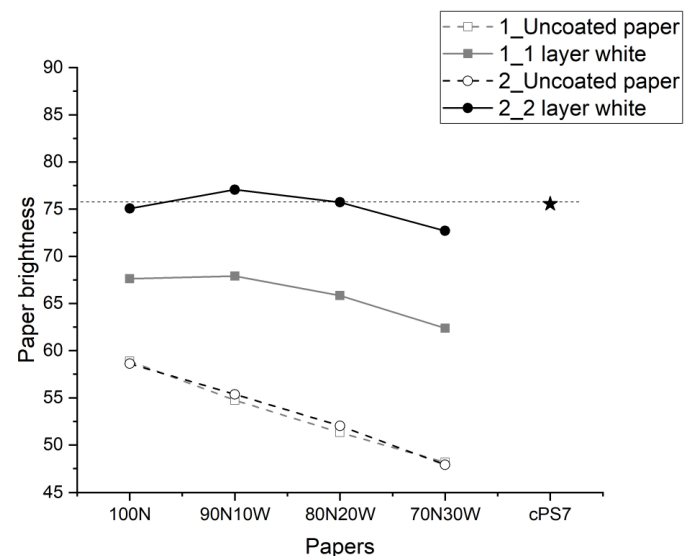

Figure 8: Influence of coating with titanium dioxide white ink on brightness of laboratory papers with wheat pulp compared to commercial papers cPS7

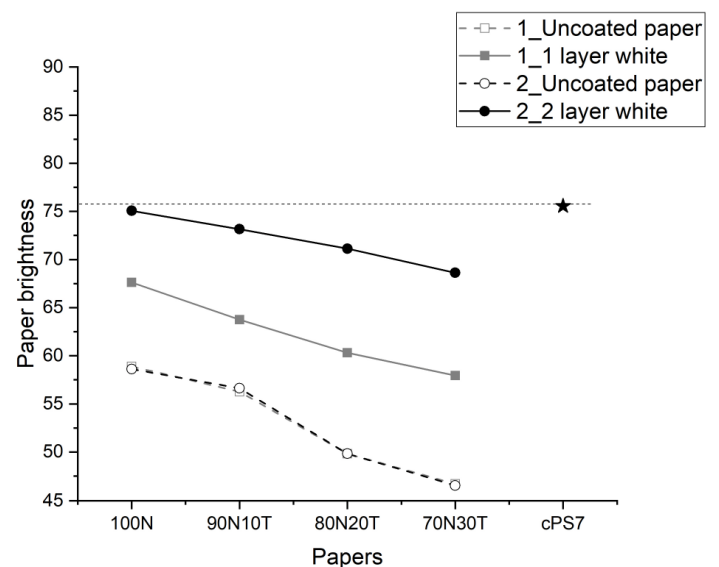

Figure 10: Influence of coating with titanium dioxide white ink on brightness of laboratory papers with triticale pulp compared to commercial papers cPS7
Coated and uncoated laboratory papers with $30 \%$ wheat pulp have the highest yellowness values of all. The highest yellowness values were measured on all the laboratory papers made from 30\% barley pulp, both uncoated and coated with one and two layers of titanium dioxide white ink. The lowest yellowness values were measured on the laboratory papers made from $100 \%$ recycled wood pulp, both coated and uncoated (Fig. 12). Figure 13 shows that, again, laboratory paper $100 \mathrm{~N}$ (coated and uncoated) has the lowest yellowness values. Among the papers containing triticale pulp, coated and uncoated, the highest yellowness values are noted for the laboratory papers with $30 \%$ triticale pulp, and the lowest for the papers with $10 \%$ triticale pulp.

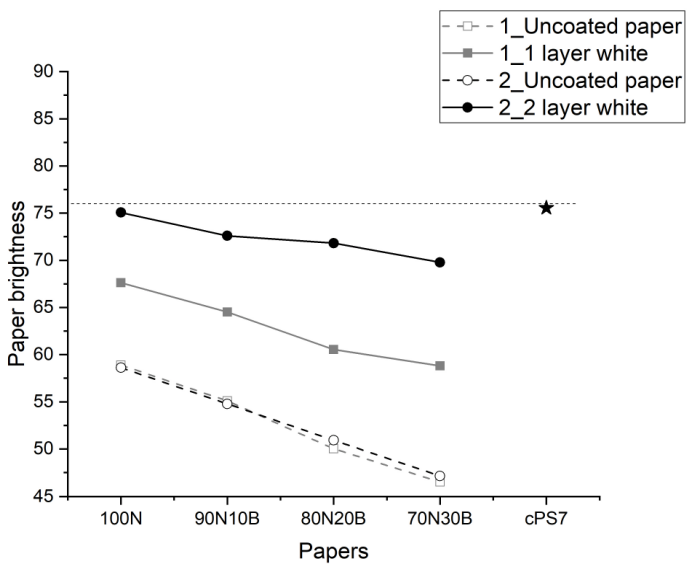

Figure 9: Influence of coating with titanium dioxide white ink on brightness of laboratory papers with barley pulp compared to commercial papers cPS7

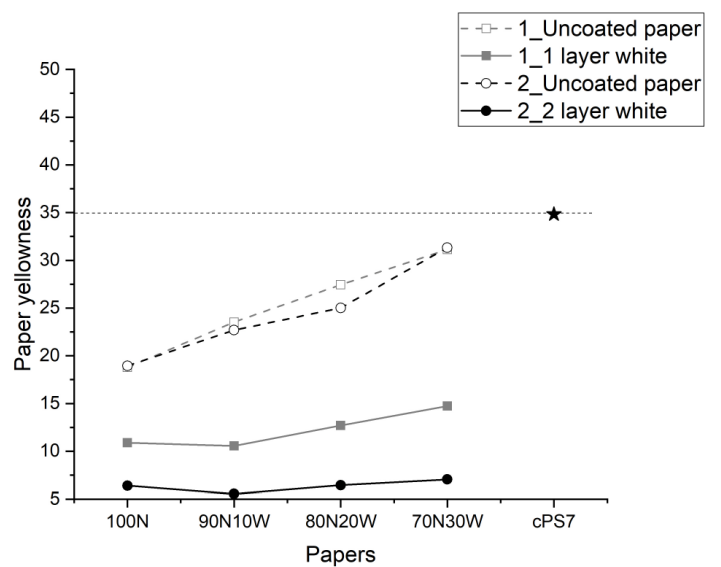

Figure 11: Influence of coating with titanium dioxide white ink on yellowness of laboratory papers with wheat pulp compared to commercial papers cPS7 


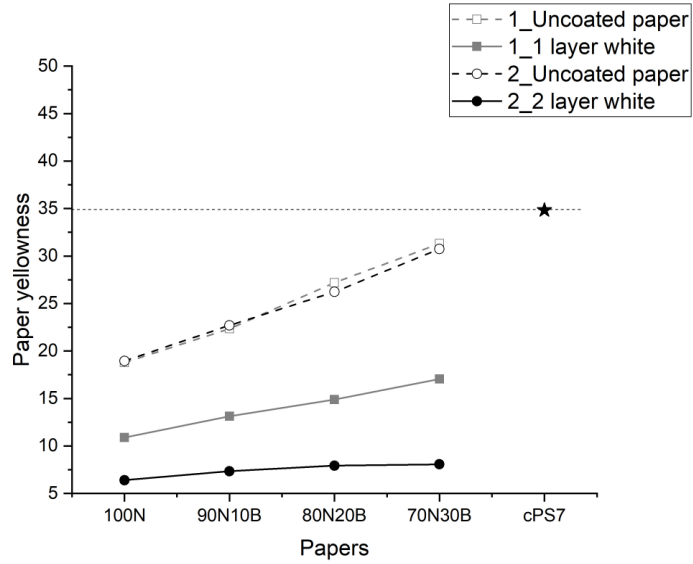

Figure 12: Influence of coating with titanium dioxide white ink on yellowness of laboratory papers with barley pulp compared to commercial papers cPS7

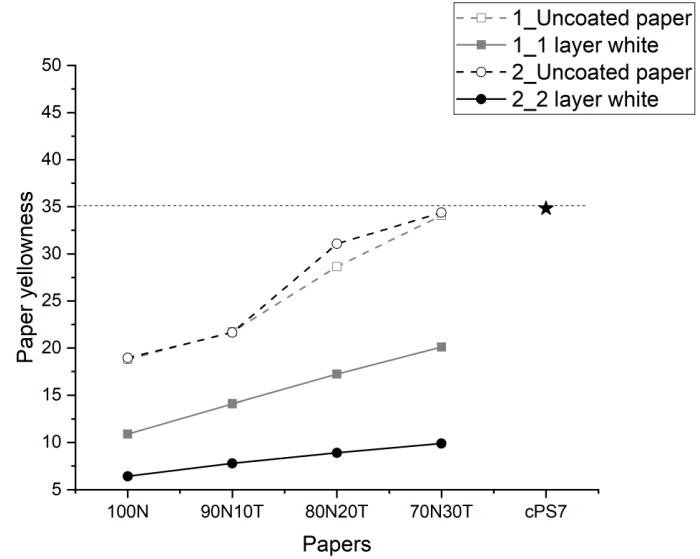

Figure 13: Influence of coating with titanium dioxide white ink on yellowness of laboratory papers with triticale pulp compared to commercial papers cPS7

Table 8

Colorimetric values

\begin{tabular}{|c|c|c|c|c|c|c|c|c|c|}
\hline \multirow{3}{*}{ Papers } & \multirow{2}{*}{\multicolumn{3}{|c|}{ Uncoated paper }} & \multicolumn{6}{|c|}{ Coated paper } \\
\hline & & & & \multicolumn{3}{|c|}{1 layer white } & \multicolumn{3}{|c|}{2 layer white } \\
\hline & $\mathrm{L}^{*}$ & $\mathrm{a}^{*}$ & $b^{*}$ & $\mathrm{~L}^{*}$ & $a^{*}$ & $\mathrm{~b}^{*}$ & $\mathrm{~L}$ & $a^{*}$ & $\mathrm{~b}^{*}$ \\
\hline $100 \mathrm{~N}$ & 87.94 & -0.10 & 7.64 & 90.13 & 0.60 & 5.16 & 92.46 & -0.05 & 2.91 \\
\hline 90N10W & 86.47 & 0.01 & 11.88 & 90.20 & 0.71 & 4.90 & 93.01 & -0.19 & 2.42 \\
\hline $80 \mathrm{~N} 20 \mathrm{~W}$ & 85.30 & 0.32 & 14.17 & 89.44 & 1.07 & 5.85 & 92.56 & 0.01 & 2.75 \\
\hline $70 \mathrm{~N} 30 \mathrm{~W}$ & 83.85 & 0.61 & 16.81 & 88.25 & 1.54 & 6.88 & 91.48 & 0.45 & 3.14 \\
\hline $90 \mathrm{~N} 10 \mathrm{~B}$ & 86.92 & 0.10 & 11.53 & 88.95 & 1.11 & 6.21 & 91.40 & 0.26 & 3.20 \\
\hline $80 \mathrm{~N} 20 \mathrm{~B}$ & 85.65 & 0.72 & 14.34 & 87.35 & 1.63 & 7.14 & 91.02 & 0.51 & 3.37 \\
\hline $70 \mathrm{~N} 30 \mathrm{~B}$ & 84.39 & 0.90 & 14.94 & 86.86 & 2.14 & 7.83 & 90.41 & 0.83 & 3.53 \\
\hline $90 \mathrm{~N} 10 \mathrm{~T}$ & 86.92 & 0.01 & 11.69 & 88.92 & 1.03 & 6.82 & 91.72 & 0.31 & 3.62 \\
\hline $80 \mathrm{~N} 20 \mathrm{~T}$ & 86.57 & -0.03 & 12.99 & 87.95 & 1.69 & 8.48 & 90.99 & 0.70 & 3.99 \\
\hline $70 \mathrm{~N} 30 \mathrm{~T}$ & 85.77 & 0.03 & 14.04 & 87.70 & 1.95 & 9.88 & 90.52 & 1.03 & 4.50 \\
\hline PS7 (ISO 12647-2) & 89.00 & 0.00 & 3.00 & & & & & & \\
\hline cPS7 & 89.61 & 0.26 & -0.09 & & & & & & \\
\hline
\end{tabular}

\section{Colorimetric values}

CIE $\mathrm{L}^{*} \mathrm{a} \mathrm{b}^{*}$ colorimetric values for all the analysed laboratory and commercial papers are listed in Table 8.

\section{Euclidean difference}

Figure 14 (a-c) presents the calculated colorimetric difference values $\left(\Delta \mathrm{E}^{*}{ }_{00}\right)$ between the CIE L*a*b* colorimetric values (Table 8) measured for the uncoated and coated laboratory papers, with and without straw pulp, and those of commercial paper PS7 as per ISO 12647-2 standard used as reference sample.

Figure 4 (a) shows that the lowest value of colour difference is perceived on the laboratory paper made from $100 \%$ wood pulp $\left(\Delta \mathrm{E}^{*}{ }_{00}=3.8\right)$, while the laboratory papers with $30 \%$ wheat pulp $\left(\Delta \mathrm{E}^{*}{ }_{00}=10.1\right)$ and $30 \%$ barley pulp $\left(\Delta \mathrm{E}^{*}{ }_{00}=9.1\right)$ show the highest values in colour difference. These results obtained on uncoated papers were expected since unbleached straw pulp (wheat, barley or triticale) was used to form laboratory papers. The colorimetric difference values reduced significantly for all the laboratory papers after coating with one layer of titanium dioxide white ink (Fig. 14 b). The colorimetric difference values are the lowest on the laboratory paper containing $10 \%$ wheat pulp $\left(\Delta \mathrm{E}^{*}{ }_{00}=2.03\right)$, and the highest on the laboratory paper with $30 \%$ triticale pulp $\left(\Delta \mathrm{E}^{*}{ }_{00}=5.88\right)$. 


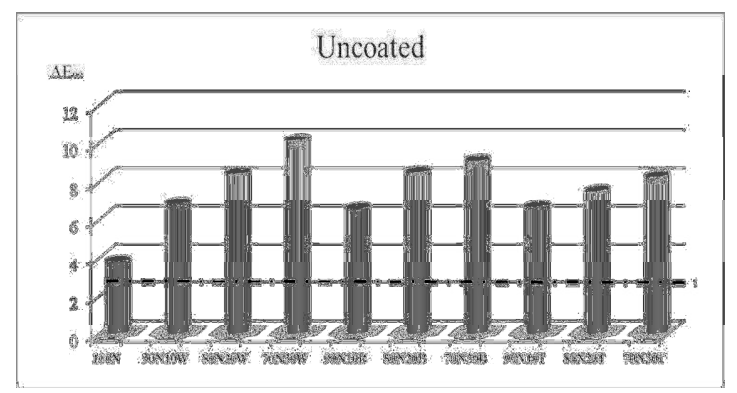

(a)

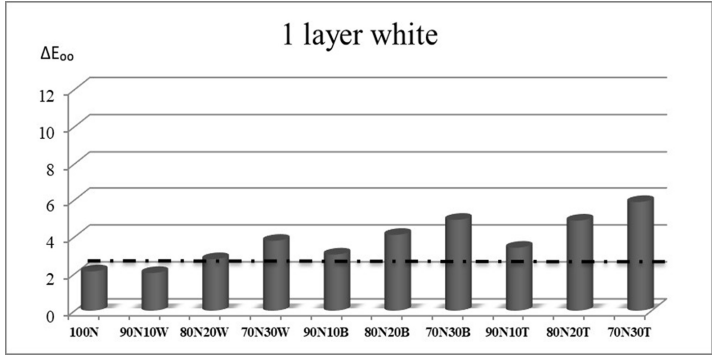

(b)

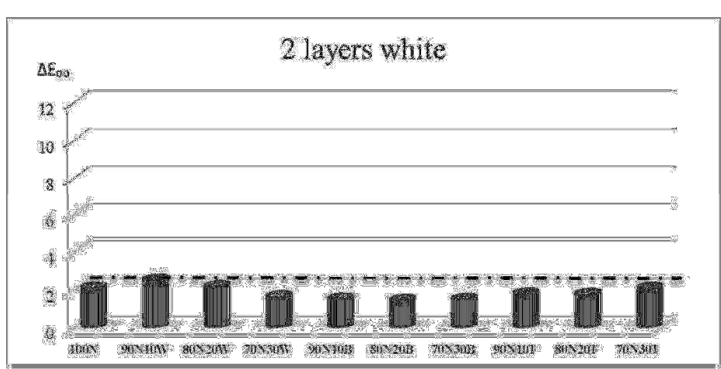

(c)

Figure 14: Colorimetric difference values $\left(\Delta \mathrm{E}^{*}{ }_{00}\right)$ between (a) uncoated laboratory papers, (b) laboratory papers coated with one layer of titanium dioxide white ink, (c) laboratory papers coated with two layers of titanium dioxide white ink, and commercial paper $\mathrm{PS} 7^{11}$ used as reference sample

It is interesting to note that the second coating of titanium dioxide white ink gave laboratory papers with straw pulp a lower value of colour difference than that of paper 100N (Fig. 15 (c)). Namely, $\Delta \mathrm{E}^{*}{ }_{00}$ calculated for the paper with $100 \%$ recycled wood pulp was 2.15 . Of all the papers containing straw, the lowest colour difference value is perceived on the laboratory paper containing $20 \%$ barley pulp $\left(\Delta \mathrm{E}^{*}{ }_{00}=1.49\right)$. The laboratory paper with $10 \%$ wheat pulp shows the highest colorimetric difference values $\left(\Delta \mathrm{E}^{*}{ }_{00}\right.$ $=2.56$ ).

\section{CONCLUSION}

This study evaluated the possibility to improve the optical properties of laboratory papers containing unbleached straw pulp by coating with titanium dioxide white ink and allowed drawing the following conclusions. Laboratory made papers, coated with one and two layers of titanium dioxide white ink achieved even better opacity values than that of commercial cPS7 paper. Whiteness values were within the range of ISO 12647 standard for all laboratory papers coated with one and two layers of titanium dioxide white ink, except the laboratory paper containing 30\% triticale pulp coated with one layer of titanium dioxide white ink. Compared to commercial paper cPS7, similar brightness values were observed for laboratory papers containing $10 \%$ and $20 \%$ wheat pulp after coating with two layers of titanium dioxide white ink. The yellowness values of all the analysed laboratory papers, regardless of their composition, are excellent, in relation to commercial paper cPS7. The best colorimetric difference values $\left(\Delta \mathrm{E}^{*}{ }_{00} \leq 2\right)$ were observed for the laboratory paper with $10 \%$ wheat pulp after coating with one layer of titanium dioxide white ink and for all laboratory papers coated with two layers of titanium dioxide white ink.

The conclusion of this study is that almost all laboratory papers with the addition of straw pulp showed satisfying optical properties after coating with titanium dioxide white ink, especially laboratory papers containing $10 \%$ and $20 \%$ straw pulp. In order to preserve the natural appearance of papers with the addition of straw, it is possible to conduct selective white printing as background for high-quality printing.

ACKNOWLEDGEMENTS: This work has been supported, in part, by the Croatian Science Foundation under the project "Printability, quality and utilization of substrates with non-wood fibres" (UIP-2017-05-2573).

\section{REFERENCES}

1 G. Fang and K. Shen, in "Global Wheat Production”, edited by Shah Fahad, Intech Open, 2018,

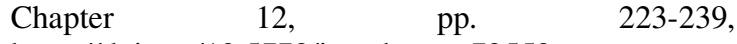
https://doi.org/10.5772/intechopen.72559 
I. Plazonić, I. Bates and Z. Barbarić-Mikočević, BioResources, 11, $5033 \quad$ (2016), https://doi.org/10.15376/biores.11.2.5033-5049

3 TAPPI T 425 om-06 Opacity of paper (15/d geometry, illuminant $\mathrm{A} / 2 *, 89 \%$ reflectance backing and paper backing), https://imisrise.tappi.org/TAPPI/Products/01/T/0104T4 25.aspx

${ }_{4}$ V. Džimbeg-Malčić, Ž. Barbarić-Mikočević and K. Itrić, Tehnički Vjesnik, 19, 191 (2012), https://hrcak.srce.hr/index.php?show=clanak\&id_clana k_jezik=117669

ISO 11475:2017 Paper and board - Determination of CIE whiteness, D65/10 degrees, https://www.iso.org/standard/63614.html

6 N. Pauler, "Paper Optics. Optical and Colour Science Related to the Pulp and Paper Industry", AB Lorentzen \& Wettre, Sweden, 2012

R. H. Leach, R. J. Pierce, E. P. Hickman, M. J. Mackenzie and H. G. Smith, "The Printing Ink Manual", Springer, 2008

8 N. Eldred, "What the Printer Should Know About Ink", $3^{\text {rd }}$ ed., GATF, 2001, p. 350

9 P. M. Kuzensof, Quantum Satis, Chemical and Technical Assessment, 2006, http://www.fao.org/fileadmin/templates/agns/pdf/jecfa/ cta/67/cta_tio2.pdf

10 I. Plazonić, Z. Barbaric-Mikocevic, V. DzimbegMalcic and I. Bates, in Procs. Natural Resources
Green Technology \& Sustainable Development/2, Zagreb, Croatia, 2016, https://pdfs.semanticscholar.org/28a7/79c9ba8bf96b3d 5e209b1a50ff03b06412f8.pdf?_ga=2.125251210.1848 117178.1589556572-1092539407.1566483448

11 ISO 12647-2:2013 Graphic technology - Process control for the production of half-tone colour separations, proof and production prints - Part 2: Offset lithographic processes, https://www.iso.org/standard/57833.html

12 Roland DG Corporation, Safety Data Sheet ECOUV, EUV-WH Ver.2 Version G_5.0, 24-May, 2019, https://www.rolanddg.com.au/-/media/roland-

apac/das/files/support/msds/2019/euvver2_sds_en_qa_ 0919.pdf

13 ASTM E313 - 15 Standard Practice for Calculating Yellowness and Whiteness Indices from Instrumentally Measured Color Coordinates

14 TAPPI T 452 om-08 Brightness of pulp, paper and paperboard

M. R. Luo, G. Cui and B. Rigg, Color Res. Appl., 26, 340 (2001), https://doi.org/10.1002/col.1049

16 I. Zjakić, "Upravljanje kvalitetom ofsetnog tiska" (Quality Management in Offset Printing), Hrvatska sveučilišna naklada, Zagreb, 2007

17 N. Veronovski, in "Titanium Dioxide - Material for a Sustainable Environment", IntechOpen, 2018, Chapter http://dx.doi.org/10.5772/intechopen.72945 